ZIESEMER, Henrique da Rosa; HÜLSE, Levi. A retórica da defesa do Meio Ambiente - uma perspectiva catarinense do Ministério Público. Revista Eletrônica Direito e Política, Programa de Pós-Graduação Stricto Sensu em Ciência Jurídica da UNIVALI, Itajaí, v.12, n.3, 30 quadrimestre de 2017. Disponível em: www.univali.br/direitoepolitica - ISSN 1980-7791

\title{
A RETÓRICA DA DEFESA DO MEIO AMBIENTE - UMA PERSPECTIVA CATARINENSE DO MINISTÉRIO PÚBLICO
}

\author{
THE RHETORICS OF ENVIRONMENTAL DEFENSE - A CATARINIAN PERSPECTIVE OF \\ THE PUBLIC MINISTRY
}

Henrique da Rosa Ziesemer ${ }^{1}$

Levi Hülse ${ }^{2}$

SUMÁRIO: Introdução; 1 A defesa do meio ambiente numa visão atual; 20 ministério público na defesa meio ambiente; 3 Ferramentas institucionais para a defesa do meio ambiente; 4 A Sustentabilidade além do meio ambinte; 5 A atuação do ministério público catarinense na defesa do meio ambiente; Considerações finais; Referência das Fontes.

\section{RESUMO}

A instituição do Ministério Público ganhou destaque e relevo no cenário jurídico nacional com a promulgação da Constituição de 1988. Com ele, os olhos da sociedade se voltaram para sua atuação, e as dinâmicas e constantes mudanças ideológicas e sociais, forçam a adaptação do Ministério Público, para dar as respostas adequadas às demandas que Ihes são oferecidas. O Ministério Público pode ser visto como um poder, não de Estado, mas da sociedade, em sua própria defesa. É nesse contexto que a instituição atua na busca da defesa da ordem jurídica, em especial, o Art. 255 da Constituição Federal. Contudo, mesmo com o reconhecido esforço, o arcabouço de demandas ambientais não é estancado, o que forçará o Ministério Público a aprimorar sua forma de atuação.

PALAVRAS-CHAVE: Ministério Público; Meio Ambiente; Sustentabilidade; Atuação

1 Possui graduação em Direito pela Universidade do Vale do Itajaí (1999). Doutorando em Ciência Jurídica pela UNIVALI Mestre em Ciência Jurídica pela UNIVALI (2013), especialista em Direito Processual Penal pela UNIVALI (2008), e Direito Administrativo pela CESUSC (2004). É Promotor de Justiça do Ministério Público do Estado de Santa Catarina, e professor da Escola do Ministério Público de Santa Catarina e da Magistratura. E-mail: henry-sc@uol.com.br.

2 Doutorando em Ciência Jurídica pela Universidade do Vale do Itajaí- UNIVALI - SC, na área de concentração em Constitucionalismo, Transnacionalidade e Produção do Direito. Mestre em Ciência Jurídica pela UNIVALI. Graduado Bacharel em Direito pela Fundação Universidade Regional de Blumenau FURB (2010) e graduado em História pela Fundação Universidade Regional de Blumenau FURB (2006). Advogado com a OAB/SC 31.986. Professor na Universidade do Alto Vale do Rio do Peixe - UNIARP. Editor da Revista Ponto de Vista Jurídico - UNIARP. O autor agradece ao Fundo de Apoio à Pesquisa (FAP) da UNIARP pelo apoio financeiro. levi@uniarp.edu.br. 
ZIESEMER, Henrique da Rosa; HÜLSE, Levi. A retórica da defesa do Meio Ambiente - uma perspectiva catarinense do Ministério Público. Revista Eletrônica Direito e Política, Programa de Pós-Graduação Stricto Sensu em Ciência Jurídica da UNIVALI, Itajaí, v.12, n.3, 30 quadrimestre de 2017. Disponível em: www.univali.br/direitoepolitica - ISSN 1980-7791

\section{ABSTRACT}

The institution of the Public Prosecutor's Office gained prominence and prominence in the national legal scenario with the promulgation of the Constitution of 1988. With it, the eyes of society turned to its action, and the dynamic and constant ideological and social changes, forced the adaptation of the Public Prosecution Service, In order to give adequate answers to the demands that are offered to them. The Public Prosecutor's Office can be seen as a power, not of state, but of society, in its own defense. It is in this context that the institution acts in the search for the defense of the juridical order, especially, Art. 255 of the Federal Constitution. However, even with the acknowledged effort, the framework of environmental demands is not stagnant, which will force the Public Ministry to improve its way of acting.

KEYWORDS: Public Ministry - Environment - Sustainability - Performance

\section{INTRODUÇÃO}

Com a Constituição da República Federativa do Brasil $^{3}$ promulgada em 1988, o Ministério Público, como instituição essencial à função Jurisdicional do Estado ganhou força de atuação jurídica e administrativa, na tutela dos interesses difusos e coletivos, bem como na iniciativa da ação penal.

Através de seus princípios constitucionalmente consagrados, o Ministério Público atua na realização de suas tarefas, com funções de fiscalização, administrativas, e iniciativa de atos e procedimentos jurídico-administrativos, com o fim especial de justiça, norteado pela satisfação da sociedade. Em boa hora o constituinte dotou o Ministério Público de poderes (investigatórios, iniciativas de ações judiciais) prerrogativas e garantias, para, assim agir na busca do equilíbrio social. Entende-se que, em sua essência, busca o Ministério Público a efetivação do disposto no artigo segundo da Constituição da República de 1988, com a verdadeira harmonia entre os três Poderes, além da defesa dos interesses e direitos indisponíveis.

\footnotetext{
3 BRASIL. Constituição (1988). Constituição da República Federativa do Brasil. Brasília, DF: Senado Federal: Centro Gráfico, 1988. 292 p.
} 
ZIESEMER, Henrique da Rosa; HÜLSE, Levi. A retórica da defesa do Meio Ambiente - uma perspectiva catarinense do Ministério Público. Revista Eletrônica Direito e Política, Programa de Pós-Graduação Stricto Sensu em Ciência Jurídica da UNIVALI, Itajaí, v.12, n.3, $3^{\circ}$ quadrimestre de 2017. Disponível em: www.univali.br/direitoepolitica - ISSN 1980-7791

Este novo modelo institucional, que poderia se chamar de autêntico ombudsman confere ao Ministério Público, inclusive no que concerne à atuação fora do âmbito judicial, papel de notável importância, caracterizando-o, primordialmente, como órgão agente, responsável por levar a juízo questões relacionadas aos interesses sociais e individuais indisponíveis, no afã da robustez do Estado de Direito e do respeito à cidadania.

Essa macroatribuição do Ministério Público se operacionaliza, do ponto de vista da atividade processual, nos vários ramos do direito, ora atuando como parte da relação jurídico-processual (órgão-agente), ora como fiscal da lei (órgão interveniente).

No ponto central deste artigo, a atuação do Ministério Público catarinense. Busca-se nas linhas abaixo contextualizar a atuação da instituição na defesa do meio ambiente, tendo como parâmetro a sustentabilidade, e a interpretação extensiva de seu conceito, atrelado ao meio ambiente e à administração pública.

Procurar-se-á, não demonstrar, mas chamar a atenção para a forma de atuação ministerial atual, e a necessidade da revisão de suas atuações, na busca dos melhores resultados para a sociedade.

\section{A DEFESA DO MEIO AMBIENTE NUMA VISÃo ATUAL}

A defesa do meio ambiente, em termos ecológicos, está prevista no Art. 225, da Constituição Federal ${ }^{4}$ :

Art. 225. Todos têm direito ao meio ambiente ecologicamente equilibrado, bem de uso comum do povo e essencial à sadia qualidade de vida, impondo-se ao Poder Público e à coletividade o dever de defendê-lo e preservá- lo para as presentes e futuras gerações.

4 BRASIL. Constituição (1988). Constituição da República Federativa do Brasil. Brasília, DF: Senado Federal: Centro Gráfico, 1988. 292 p. 
ZIESEMER, Henrique da Rosa; HÜLSE, Levi. A retórica da defesa do Meio Ambiente - uma perspectiva catarinense do Ministério Público. Revista Eletrônica Direito e Política, Programa de Pós-Graduação Stricto Sensu em Ciência Jurídica da UNIVALI, Itajaí, v.12, n.3, 30 quadrimestre de 2017. Disponível em: www.univali.br/direitoepolitica - ISSN 1980-7791

O meio ambiente ecologicamente equilibrado se traduz em pressuposto para a manutenção da vida com qualidade no planeta, com reflexos diretos em questões sociais, econômicas, e políticas. Vários são os tratados e acordos sobre o tema em nível global, cujos objetivos variam desde debates sobre os rumos a serem seguidos, até questões pontuais localizadas.

Nos diversos países preocupados com a questão ambiental, o trato com o tema se dá de diferentes formas. Contudo, um os pontos convergentes reside no fato de que setores destacados do poder público tornam-se responsáveis por ações relativas ao meio ambiente, tanto na questão de defesa e preservação, assim como na questão de exploração e realização de atividades econômicas.

Não é uma tarefa fácil equilibrar todos os interesses, mormente porque no atual estágio de evolução social, a questão econômica fala muito alto e não raras vezes acaba se sobrepondo a temas ambientais delicados, como reservas de água potável, fauna, e aquecimento global, que já mostram claramente seus efeitos.

De qualquer forma, em especial no Brasil, há instituições dedicadas e especializadas no trato com o meio ambiente, e capazes de questionar, judicial, e extrajudicialmente, o poder público e as forças políticas e econômicas, em questões ambientais, visando o cumprimento da Constituição de das leis.

Não se trata de uma disputa entre o bem e o mal, ou entre o certo e o errado, mas sim da existência de mecanismos capazes de realizar um contraponto quando a questão é o trato com o meio ambiente (e diversas outras).

No contexto brasileiro, é extremamente comum a observâncias de danos ambientais, que ocorrer em maior e menor escala, de forma individual, ou coletiva. O não cumprimento, ou a flexibilização das exigências legais para a utilização do meio ambiente são decorrentes de despreparo e corrupção, e comprometem cada vez mais a qualidade de vida. A legislação burocratizada e a corrupção fazem com que a recuperação de danos ambientais seja muito mais lenta do que a ocorrência 
ZIESEMER, Henrique da Rosa; HÜLSE, Levi. A retórica da defesa do Meio Ambiente - uma perspectiva catarinense do Ministério Público. Revista Eletrônica Direito e Política, Programa de Pós-Graduação Stricto Sensu em Ciência Jurídica da UNIVALI, Itajaí, v.12, n.3, 30 quadrimestre de 2017. Disponível em: www.univali.br/direitoepolitica - ISSN 1980-7791

daqueles, podendo-se facilmente sustentar que o disposto no Art. 225 da Constituição Federal é quase letra morta, quando cotejado com a realidade posta.

Há, no Estado Brasileiro, como dito alhures, uma série de instituições, governamentais, ou não, com atribuições específicas para defesa do meio ambiente. Essas instituições são distribuídas pelos três níveis da federação, sejam federal, estadual e municipal, e as públicas são dotadas, via de regra, de poder de polícia ${ }^{5}$, e força coercitiva. O poder de polícia, como toda ação da Administração, é submetido ao princípio da legalidade e controle jurisdicional. O poder de polícia possui como finalidade, a proteção e satisfação do interesse público, em sentido amplo. Engloba a proteção à moral, saúde pública, meio ambiente, e até a segurança nacional. Possui como atributos a discricionariedade, auto- executoriedade e coercibilidade.

Destacam-se, nesse cenário, as Secretarias Estaduais e Municipais do meio ambiente, Polícia Militar Ambiental, Fundações com objetivos ambientais, assim como o Ministério Público (MP).

Cada uma das instituições declinadas acima possui uma função específica dentro gênero defesa do meio ambiente. Desataca-se, em especial e para fins do presente artigo, o Ministério Público, por ser a instituição constitucionalmente formatada para contestar todas as demais, além de contestar as forças políticas e econômicas. É claro que com essas ponderações, não se deseja atribuir razão a um segmento em detrimento dos demais, mas sim proceder á uma análise da atuação ministerial na defesa do meio ambiente, restringindo a abrangência ao Estado de Santa Catarina.

\footnotetext{
5 BRASIL. Lei no 5.172, de 25 de outubro de 1966. Dispõe sobre o Sistema Tributário Nacional e institui normas gerais de direito tributário aplicáveis à União, Estados e Municípios.Código Tributário Nacional. disponível em http://www.planalto.gov.br/ccivil_03/leis/L5172Compilado.htm. Acesso em 10 fev. 2017. Art. 78. Considera-se poder de polícia atividade da administração pública que, limitando ou disciplinando direito, interesse ou liberdade, regula a prática de ato ou a abstenção de fato, em razão de interesse público concernente à segurança, à higiene, à ordem, aos costumes, à disciplina da produção e do mercado, ao exercício de atividades econômicas dependentes de concessão ou autorização do Poder Público, à tranqüilidade pública ou ao respeito à propriedade e aos direitos individuais ou coletivos.
} 
ZIESEMER, Henrique da Rosa; HÜLSE, Levi. A retórica da defesa do Meio Ambiente - uma perspectiva catarinense do Ministério Público. Revista Eletrônica Direito e Política, Programa de Pós-Graduação Stricto Sensu em Ciência Jurídica da UNIVALI, Itajaí, v.12, n.3, 30 quadrimestre de 2017. Disponível em: www.univali.br/direitoepolitica - ISSN 1980-7791

\section{MINISTÉRIO PÚBLICO NA DEFESA MEIO AMBIENTE}

A definição técnica do Ministério Público vem descrita no Art. 127 da Constituição Federal ${ }^{6}$ :

Art. 127. O Ministério Público é instituição permanente, essencial à função jurisdicional do Estado, incumbindo-Ihe a defesa da ordem jurídica, do regime democrático e dos interesses sociais e individuais indisponíveis.

Não se pretende, no presente artigo, discorrer com profundidade acerca do Ministério Público, ou de suas origens, mas sim sobre suas formas e ferramentas de atuação previstas na Constituição e nas leis.

No ponto central da discussão que ora se trava, em sede de defesa do meio ambiente, esta atuação está inserta na parte final do artigo 127, sobretudo nos interesses sociais e individuais indisponíveis. O Ministério Público tem suas funções previstas na Constituição Federal, sendo estas regulamentadas na forma da lei. Através de uma análise do artigo retro, percebe-se que as funções previstas ao MP são eminentemente de cunho social e interesse público.

O meio ambiente, por sua vez, pode ser tutelado a título de direito difuso ${ }^{7}$, porquanto pertencente a um número indeterminável de pessoas. Vale dizer, ninguém é dono do meio ambiente, que por sua vez, pertence a todos, indistintamente.

Como preceitua Hely Lopes Meirelles ${ }^{8}$ :

\footnotetext{
6 BRASIL. Constituição (1988). Constituição da República Federativa do Brasil. Brasília, DF: Senado Federal: Centro Gráfico, 1988. 292 p.

7 Brasil. Lei 8.078, de 11.9.1990. Dispõe sobre a proteção do consumidor e dá outras providências. Publicado no DOU de 12.9.1990. Art. 81 [...] I - interesses ou direitos difusos, assim entendidos, para efeitos deste código, os transindividuais, de natureza indivisível, de que sejam titulares pessoas indeterminadas e ligadas por circunstâncias de fato [...]. Disponível em http://www.planalto.gov.br/ccivil_03/leis/L8078.htm. Acesso em 10 fev. 2017.

8 MEIRELLES. Hely Lopes. Direito Administrativo Brasileiro. São Paulo: Malheiros, 26.ed., 2001, p. 484
} 
ZIESEMER, Henrique da Rosa; HÜLSE, Levi. A retórica da defesa do Meio Ambiente - uma perspectiva catarinense do Ministério Público. Revista Eletrônica Direito e Política, Programa de Pós-Graduação Stricto Sensu em Ciência Jurídica da UNIVALI, Itajaí, v.12, n.3, 30 quadrimestre de 2017. Disponível em: www.univali.br/direitoepolitica - ISSN 1980-7791

[...] no uso comum do povo os usuários são anônimos, indeterminados, e os bens utilizados o são por todos os membros da coletividade - uti universi -, razão pela qual ninguém tem o direito ao uso exclusivo ou a privilégio na utilização do bem: o direito de cada indivíduo limita-se à igualdade com os demais na fruição do bem ou no suportar os ônus dele resultantes. Pode-se dizer que todos são iguais perante os bens de uso comum do povo.

Uma degradação ambiental atinge à toda a coletividade, indistintamente, o que caracteriza o papel do Ministério Público, como órgão pró - ativo, na qualidade de legitimado extraordinário. O Ministério Público recebeu a atribuição permanente de defesa de célebres interesses públicos (enquanto gênero), tais como a defesa do ordenamento jurídico, da democracia, dos interesses sociais e individuais indisponíveis, dentre outros. Na verdade, o texto constitucional atribuiu-lhe o dever de zelar pelo interesse público em geral. Para tanto, instrumentalizou a sua atuação concedendo-Ihe importantes mecanismos judiciais e extrajudiciais para a defesa dos interesses públicos (da sociedade em geral).

Este é o posicionamento do Supremo tribunal Federal ${ }^{9}$ :

EMENTA: AÇÃO CIVIL PÚBLICA. LEGITIMIDADE ATIVA. MINISTÉRIO PÚBLICO DO DISTRITO FEDERAL E TERRITÓRIOS. TERMO DE ACORDO DE REGIME ESPECIAL - TARE. POSSÍVEL LESÃO AO PATRIMÔNIO PÚBLICO. LIMITAÇÃO À ATUAÇÃO DO PARQUET. INADMISSIBILIDADE. AFRONTA AO ART. 129, III, DA CF. REPERCUSSÃO GERAL RECONHECIDA. RECURSO EXTRAORDINÁRIO PROVIDO. I - O TARE não diz respeito apenas a interesses individuais, mas alcança interesses metaindividuais, pois o ajuste pode, em tese, ser lesivo ao patrimônio público. II - A Constituição Federal estabeleceu, no art. 129, III, que é função institucional do Ministério Público,

9 BRASIL. Supremo tribunal Federal. RE 576155 / DF - DISTRITO FEDERAL. Relator(a): Min. RICARDO LEWANDOWSKI. Julgamento: 12/08/2010. Órgão Julgador: Tribunal Pleno. DJe-226 DIVULG 24-11-2010 PUBLIC 25-11-2010. REPUBLICAÇÃO: DJe-020 DIVULG 31-01-2011 PUBLIC 0102-2011. 
ZIESEMER, Henrique da Rosa; HÜLSE, Levi. A retórica da defesa do Meio Ambiente - uma perspectiva catarinense do Ministério Público. Revista Eletrônica Direito e Política, Programa de Pós-Graduação Stricto Sensu em Ciência Jurídica da UNIVALI, Itajaí, v.12, n.3, 30 quadrimestre de 2017. Disponível em: www.univali.br/direitoepolitica - ISSN 1980-7791

\begin{abstract}
dentre outras, "promover o inquérito e a ação civil pública, para a proteção do patrimônio público e social, do meio ambiente e de outros interesses difusos e coletivos". Precedentes. III - O Parquet tem legitimidade para propor ação civil pública com o objetivo de anular Termo de Acordo de Regime Especial - TARE, em face da legitimação ad causam que o texto constitucional Ihe confere para defender o erário. IV - Não se aplica à hipótese o parágrafo único do artigo $1^{\circ}$ da Lei 7.347/1985. V - Recurso extraordinário provido para que o TJ/DF decida a questão de fundo proposta na ação civil pública conforme entender.
\end{abstract}

Destarte, a defesa do meio ambiente por meio de suas ferramentas judiciais e extrajudiciais constitui uma das funções institucionais mais típicas do Ministério Público. De qualquer sorte, a atuação do MP não exclui a de outros entes, assim como a atuação em conjunto dos órgãos de defesa do meio ambiente fortalece a causa. É certo que nem sempre as instituições caminham no mesmo sentido e quando isso acontece, fragiliza-se o disposto no Art. 225 da Carta Magna.

Possui o Ministério Público também o papel fiscalizador, ou seja, deve o MP zelar para que os órgãos de defesa do meio ambiente exerçam seu papel a contento. Neste mister, possui uma série de ferramentas, as quais serão abordadas no tópico seguinte.

\title{
3 FERRAMENTAS INSTITUCIONAIS PARA A DEFESA DO MEIO AMBIENTE
}

As funções institucionais do Ministério Público estão previstas no Art. 129 da Constituição Federal ${ }^{10}$ :

Art. 129. São funções institucionais do Ministério Público:

I - promover, privativamente, a ação penal pública, na forma da lei;

II - zelar pelo efetivo respeito dos Poderes Públicos e dos serviços de relevância pública aos direitos assegurados nesta

10 BRASIL. Constituição (1988). Constituição da República Federativa do Brasil. Brasília, DF: Senado Federal: Centro Gráfico, 1988. 292 p. 
ZIESEMER, Henrique da Rosa; HÜLSE, Levi. A retórica da defesa do Meio Ambiente - uma perspectiva catarinense do Ministério Público. Revista Eletrônica Direito e Política, Programa de Pós-Graduação Stricto Sensu em Ciência Jurídica da UNIVALI, Itajaí, v.12, n.3, 30 quadrimestre de 2017. Disponível em: www.univali.br/direitoepolitica - ISSN 1980-7791

Constituição, promovendo as medidas necessárias a sua garantia;

III - promover o inquérito civil e a ação civil pública, para a proteção do patrimônio público e social, do meio ambiente e de outros interesses difusos e coletivos;

IV - promover a ação de inconstitucionalidade ou representação para fins de intervenção da União e dos Estados, nos casos previstos nesta Constituição;

$V$ - defender judicialmente os direitos e interesses das populações indígenas;

VI - expedir notificações nos procedimentos administrativos de sua competência, requisitando informações e documentos para instruí-los, na forma da lei complementar respectiva;

VII - exercer o controle externo da atividade policial, na forma da lei complementar mencionada no artigo anterior;

VIII - requisitar diligências investigatórias e a instauração de inquérito policial, indicados os fundamentos jurídicos de suas manifestações processuais;

IX - exercer outras funções que the forem conferidas, desde que compatíveis com sua finalidade, sendo-lhe vedada a representação judicial e a consultoria jurídica de entidades públicas.

§ 10 A legitimação do Ministério Público para as ações civis previstas neste artigo não impede a de terceiros, nas mesmas hipóteses, segundo o disposto nesta Constituição e na lei. [...]

Do texto constitucional retro, pode-se verificar com clarividência, que a proteção ao meio ambiente é expressamente mencionada no inciso III. O Inquérito Civil nasceu com a Lei de Ação Civil Pública (Lei n. 7.347/85), sendo posteriormente consagrado pela própria Constituição Federal de 1988 (art. 129, III), operando verdadeira revolução no Ministério Público. É um instrumento de investigação administrativa prévia, presidido e arquivado pelo Ministério Público. Trata-se de um procedimento administrativo, extrajudicial, de natureza inquisitorial, com objetivo de colheita de dados e informações para o futuro ingresso de ação civil pública, ou outras 
ZIESEMER, Henrique da Rosa; HÜLSE, Levi. A retórica da defesa do Meio Ambiente - uma perspectiva catarinense do Ministério Público. Revista Eletrônica Direito e Política, Programa de Pós-Graduação Stricto Sensu em Ciência Jurídica da UNIVALI, Itajaí, v.12, n.3, 30 quadrimestre de 2017. Disponível em: www.univali.br/direitoepolitica - ISSN 1980-7791

decorrências (Termos de Ajustamento de Conduta, Recomendações, etc...). A ação civil pública é instrumento processual regulamentado pela Lei $n^{\circ} 7.347 / 85^{11}$ e se destina a reprimir ou impedir os danos causados ao meio ambiente, consumidor, bens e direitos de valor histórico, estético, artístico, turístico ou paisagístico, além de qualquer outro interesse difuso ou coletivo.

Além do referido inciso, a proteção ao meio ambiente pode ser exercida por meio das ferramentas colocadas nos incisos I, IV, VI e VIII. No inciso I, os institutos da transação penal, e suspensão condicional do processo, por exemplo, previstos na lei $9.099 / 95^{12}$, são importantes mecanismos que podem forçar o poluidor a reparar o dano ambiental causado.

No caso do inciso IV, uma importante função institucional, no âmbito do Ministério Público estadual, é o ajuizamento de ação direta de inconstitucionalidade contra lei municipal em face à Constituição do Estado, lei esta que em tese viola a defesa do meio ambiente. Em âmbito estadual, especialmente em Santa Catarina, o Procurador Geral de Justiça e os Promotores de Justiça em primeiro grau, podem impetrar ações diretas de inconstitucionalidade perante o Tribunal de Justiça de Santa Catarina, de lei ou ato normativo estadual ou municipal e face da Constituição do Estado de Santa Catarina. Estas atribuições estão previstas na Lei Complementar no 197 de $2000^{13}$, Lei Orgânica do Ministério Público catarinense:

Art. 93. Além de outras previstas em normas constitucionais ou legais, são atribuições processuais do Procurador-Geral de Justiça:

\footnotetext{
11 BRASIL. Lei 0 7.347, de 24 de julho de 1985, Disciplina a ação civil pública de responsabilidade por danos causados ao meio-ambiente, ao consumidor, a bens e direitos de valor artístico, estético, histórico, turístico e paisagístico e dá outras providências. Publicado no D.O.U em 25.7.1985. Dispovel em http://www.planalto.gov.br/ccivil_03/leis/L7347orig.htm. Acesso em 10 fev. 2017.

12 BRASIL. Lei no 9.099 de 26 de setembro de 1995. Dispõe sobre os Juizados Especiais Cíveis e Criminais e dá outras providências. http://www.planalto.gov.br/ccivil_03/leis/L9099.htm. Acesso em 10 fev. 2017.

13 SANTA CATARINA. Lei Complementar no 197, de 13.7.2000. Institui a Lei Orgânica do Ministério Público e adota outras providências. Publicada no DO no 16.455 de 14.7.2000. Disponível em 200.192.66.20/alesc/docs/2000/197_2000_lei_complementar.doc. Acesso em 10 fev. 2017.
} 
ZIESEMER, Henrique da Rosa; HÜLSE, Levi. A retórica da defesa do Meio Ambiente - uma perspectiva catarinense do Ministério Público. Revista Eletrônica Direito e Política, Programa de Pós-Graduação Stricto Sensu em Ciência Jurídica da UNIVALI, Itajaí, v.12, n.3, 30 quadrimestre de 2017. Disponível em: www.univali.br/direitoepolitica - ISSN 1980-7791

VI - propor ação de inconstitucionalidade de lei ou ato normativo estadual ou municipal, contestados em face da Constituição Estadual e ação de inconstitucionalidade por omissão em face de preceito da Constituição Estadual;

$[\ldots]$

Art. 99. Cabe aos Promotores de Justiça exercer as atribuições de Ministério Público junto aos órgãos jurisdicionais de primeira instância, competindo-lhes, ainda:

III - propor ação direta de inconstitucionalidade de lei ou ato normativo municipal, em face da Constituição Estadual, e a ação de inconstitucionalidade por omissão, em face de preceito da Constituição Estadual, no âmbito dos municípios de sua atuação.

O inciso VI se traduz na materialização das investigações e procedimentos trabalhados pelo MP. A requisição de documento e informações no exercício das funções institucionais se traduz em verdadeira ordem legal, não podendo o destinatário recusar seu cumprimento. Aliás, o não atendimento às requisições ministeriais pode caracterizar o crime previsto no art. $10^{14}$ da Lei $73.47 / 85$ :

Art. 10. Constitui crime, punido com pena de reclusão de 1 (um) a 3 (três) anos, mais multa de 10 (dez) a 1.000 (mil) Obrigações Reajustáveis do Tesouro Nacional - ORTN, a recusa, o retardamento ou a omissão de dados técnicos indispensáveis à propositura da ação civil, quando requisitados pelo Ministério Público.

Também existe a possibilidade da recusa ser caracterizada como ato de improbidade administrativa, por ofensa aos princípios da administração.

As requisições atendem ao princípio da legalidade, especialmente no que se refere à defesa do meio ambiente, quando o poder público é contestado. O Ministério Público atua diretamente em tais casos, em grande parte das vezes em situações de

14 BRASIL. Lei no 7.347, de 24 de julho de 1985. Disciplina a ação civil pública de responsabilidade por danos causados ao meio-ambiente, ao consumidor, a bens e direitos de valor artístico, estético, histórico, turístico e paisagístico (VETADO) e dá outras providências. Disponível em http://www.planalto.gov.br/ccivil_03/leis/L7347orig.htm. Acesso em 10 fev. 2017. 
ZIESEMER, Henrique da Rosa; HÜLSE, Levi. A retórica da defesa do Meio Ambiente - uma perspectiva catarinense do Ministério Público. Revista Eletrônica Direito e Política, Programa de Pós-Graduação Stricto Sensu em Ciência Jurídica da UNIVALI, Itajaí, v.12, n.3, 30 quadrimestre de 2017. Disponível em: www.univali.br/direitoepolitica - ISSN 1980-7791

concessões de licenças ambientais duvidosas, ou alvarás para a instalação de determinadas atividades.

Conjugado com o inciso VI, tem-se o inciso VIII, notadamente no que tange à requisição de diligências investigatórias. Como mencionado alhures, a requisição é uma ordem legal, e quando o Ministério Público requisita uma diligência investigatória em defesa do meio ambiente, equivale dizer que, nos termos da lei, ordena que determinado ente público compareça a determinado local e atue conforme suas prerrogativas. Neste campo, pode o Ministério Público exigir, dentro desta mesma diligência, que o órgão atuante tome todas as medidas administrativas cabíveis, quando se deparar com uma infração ambiental. Vale dizer, embargo, multa, suspensão de atividades, etc...

\section{A SUSTENTABILIDADE ALÉM DO MEIO AMBIENTE}

O conceito de sustentabilidade não é estanque. Ousa-se dizer que a questão da sustentabilidade pode evoluir juntamente com a evolução global e que atualmente, não se deve mais falar em sustentabilidade atrelada apenas à questões ambientais.

A sustentabilidade está relacionada à gestão, seja ela ambiental, seja financeira, ou mesmo da administração pública.

Segundo Uaçai de Magalhães Lopes e Robinson Moreira Tenório ${ }^{15}$ :

[...] sustentabilidade é um princípio de atuação de uma sociedade que mantém as características necessárias para um sistema social justo, ambientalmente equilibrado e economicamente próspero, por um período de tempo longo e indefinido. Atende, assim, às necessidades das gerações do presente sem comprometer a possibilidade das gerações futuras atenderem às suas próprias necessidades.

Irina Mikhailova1617, ao tratar do tema, assim pontua:

15 LOPES, Uaçai de Magalhães; TENÓRIO, Robinson Moreira. Educação como fundamento da sustentabilidade. Salvador: EDUFBA, 2011. p.76. 
ZIESEMER, Henrique da Rosa; HÜLSE, Levi. A retórica da defesa do Meio Ambiente - uma perspectiva catarinense do Ministério Público. Revista Eletrônica Direito e Política, Programa de Pós-Graduação Stricto Sensu em Ciência Jurídica da UNIVALI, Itajaí, v.12, n.3, 30 quadrimestre de 2017. Disponível em: www.univali.br/direitoepolitica - ISSN 1980-7791

No presente contexto considera-se (Na nossa opinião, ) que o sentido mais importante da sustentabilidade é que ela simplesmente representa a justiça em relação às gerações futuras.

Segundo Klaus Bosselmann ${ }^{18}$ :

Sustentabilidade e justiça evocam sentimentos semelhantes. Em alguns aspectos, no entanto, a sustentabilidade parece mais distante do que a justiça. Há várias razões para isso. Primeiro, muitas das sociedades de hoje podem ser descritas como justas, pelo menos no sentido de prover os meios para a resolução pacífica dos conflitos. Em contraste, nenhuma das sociedades de hoje é sustentável.

Destarte, pode-se ponderar que a questão da sustentabilidade vai muito além do meio ambiente, traduzindo uma carga valorativa de atividade que pode ser aplicada, por exemplo, ao Ministério Público. Quando o texto constitucional menciona ser uma das funções institucionais do MP a defesa do meio ambiente, de forma implícita insere em sua atuação conceitos que remetem à sustentabilidade, que deixa de ser uma forma de atuação retórica.

De fato, em que pese a incidência de uma visão e atuação de natureza sustentável no âmbito do Ministério Público, não se pode afirmar, com alguma margem de segurança, ao menos numa perspectiva de Santa Catarina, se toda a força empreendida, e todo o gasto com a máquina pública repercutem necessariamente na eficiência esperada, conceito este alçado à categoria de princípio constitucional.

\footnotetext{
16 Professora do Departamento de Ciências Econômicas da UFSM.

17MIKHAILOVA, Irina. SUSTENTABILIDADE: EVOLUÇÃo DOS CONCEITOS TEÓRICOS E OS PROBLEMAS DA MENSURAÇÃO PRÁTICA. Revista Economia e Desenvolvimento, ISSN: 1414-6509. $\mathrm{n}^{\circ}$ 16, 2004. p.22-41.

18 BOSSELMANN, Klaus. O princípio da sustentabilidade: transformando direito e governança. Tradução de Phillip Gil França. São Paulo: Revista dos Tribunais, 2015, p. 26.
} 
ZIESEMER, Henrique da Rosa; HÜLSE, Levi. A retórica da defesa do Meio Ambiente - uma perspectiva catarinense do Ministério Público. Revista Eletrônica Direito e Política, Programa de Pós-Graduação Stricto Sensu em Ciência Jurídica da UNIVALI, Itajaí, v.12, n.3, 30 quadrimestre de 2017. Disponível em: www.univali.br/direitoepolitica - ISSN 1980-7791

\section{A ATUAÇão do ministério público catarinense na defesa do MEIO AMBIENTE}

Em um recente, no ano de 2015, pode-se analisar os dados da atuação do Ministério Público Catarinense, em seu Relatório de Gestão Institucional19 2015.

Segundo consta do referido Relatório ${ }^{20}$, o objetivo é:

Promover as medidas necessárias para garantir às presentes e futuras gerações o direito a um meio ambiente ecologicamente equilibrado e ao desenvolvimento sustentável.

Destarte, a sustentabilidade é uma premissa e uma preocupação do Ministério Público de Santa Catarina, que desenvolve sua atribuição ambiental permeado pelos conceitos aplicáveis.

Como se observa do documento institucional, foram realizados diversos programas, dentre eles o programa "LIXO NOSSO DE CADA DIA", cujo objetivo é " Promover a recuperação de áreas degradadas, a destinação final ambientalmente adequada de resíduos sólidos, além de estimular os órgãos de execução a exigir implantação de políticas públicas ${ }^{21 "}$. Dentro do programa mencionado, pode-se aplicar os conceitos e valores da sustentabilidade, máxime quando invocada pelo próprio órgão atuante.

\footnotetext{
19 SANTA CATARINA. Ministério Público. Relatório de gestão institucional 2015. Florianópolis: MPSC, $2016 . \quad$ Disponível em: https://documentos.mpsc.mp.br/portal/manager/resourcesDB.aspx?path=1965. Acesso em 10 fev. 2017.

20 SANTA CATARINA. Ministério Público. Relatório de gestão institucional 2015. Florianópolis: MPSC, $2016 . \quad$ Disponível em: https://documentos.mpsc.mp.br/portal/manager/resourcesDB.aspx?path=1965. Acesso em 10 fev. 2017. P. 61

21 SANTA CATARINA. Ministério Público. Relatório de gestão institucional 2015. Florianópolis: MPSC, $2016 . \quad$ Disponível em: https://documentos.mpsc.mp.br/portal/manager/resourcesDB.aspx?path=1965. Acesso em 10 fev. 2017. P. 61
} 
ZIESEMER, Henrique da Rosa; HÜLSE, Levi. A retórica da defesa do Meio Ambiente - uma perspectiva catarinense do Ministério Público. Revista Eletrônica Direito e Política, Programa de Pós-Graduação Stricto Sensu em Ciência Jurídica da UNIVALI, Itajaí, v.12, n.3, $3^{\circ}$ quadrimestre de 2017. Disponível em: www.univali.br/direitoepolitica - ISSN 1980-7791

Outra iniciativa interessante na defesa do meio ambiente, que leva em conta valores sustentáveis, é o que o Relatório de Gestão Institucional chama de "Diálogos Interinstitucionais"22. Nessa iniciativa, o MPSC promoveu um encontro de integração com vários órgãos ambientais catarinenses. Dos resultados demonstrados, foram padronizados procedimentos e protocolos em benefício do meio ambiente, em especial o trâmite de documentos administrativos, e busca de atuações conjuntas.

Já no que se refere à atuação do Ministério Público em primeiro grau na defesa do meio ambiente, levando-se em conta as ferramenta apresentadas acima, observase que no ano de 2014 houve uma demanda criminal ambiental de 3.520 feitos, ao passo que em 2015, foram registrados 3.459, havendo uma sensível redução de $1,73 \%$ nas atividades criminais que envolvem a área ambiental ${ }^{23}$.

Na área cível, mais diretamente afeta à causa ambiental, de 2014 para 2015 houve um acréscimo de $11,83 \%$ de ações civis públicas ajuizadas, sendo 2.917 em 2014, e 3.262 em 2015, no todo (p. 165). Especificamente na defesa do meio ambiente, em 2014 foram ajuizadas 323 ações civis públicas, ao passo em 2015 foram 237, uma sensível incrementação de $1,24 \%$ na atuação cível processual ${ }^{24}$.

\footnotetext{
22 SANTA CATARINA. Ministério Público. Relatório de gestão institucional 2015. Florianópolis: MPSC, $2016 . \quad$ Disponível em: https://documentos.mpsc.mp.br/portal/manager/resourcesDB.aspx?path=1965. Acesso em 10 fev. 2017. P. 67

${ }^{23}$ SANTA CATARINA. Ministério Público. Relatório de gestão institucional 2015. Florianópolis: MPSC, $2016 . \quad$ Disponível em: https://documentos.mpsc.mp.br/portal/manager/resourcesDB.aspx?path=1965. Acesso em 10 fev. 2017. P. 157.

24 SANTA CATARINA. Ministério Público. Relatório de gestão institucional 2015. Florianópolis: MPSC, $2016 . \quad$ Disponível em: https://documentos.mpsc.mp.br/portal/manager/resourcesDB.aspx?path=1965. Acesso em 10 fev. 2017. P. 168.
} 
ZIESEMER, Henrique da Rosa; HÜLSE, Levi. A retórica da defesa do Meio Ambiente - uma perspectiva catarinense do Ministério Público. Revista Eletrônica Direito e Política, Programa de Pós-Graduação Stricto Sensu em Ciência Jurídica da UNIVALI, Itajaí, v.12, n.3, $3^{\circ}$ quadrimestre de 2017. Disponível em: www.univali.br/direitoepolitica - ISSN 1980-7791

Em relação aos inquéritos civis, na defesa ambiental, de 2014 para 2015 houve um acréscimo de 4,88\%, passando de 3.773 para 3.957 inquéritos civis ambientais instaurados ${ }^{25}$.

Por certo, o que se deseja não é uma análise exaustiva de números da atuação ministerial em Santa Catarina, mas nesta breve passagem já pode ser observado que o Ministério Público de Santa Catarina adota uma postura e pauta sua atuação pela busca da eficiência, levando em conta a sustentabilidade a ser perseguida. Os programas desenvolvidos, bem como a atuação processual e suas diretrizes colocam a instituição na vanguarda pela busca da almejada sustentabilidade, seja no meio ambiente, seja na administração pública.

Contudo, em que pese os esforços reconhecidos, bem como os resultados demonstrados, é necessária a indagação se os resultados são satisfatórios em prol da coletividade.

Tem-se em uma análise preliminar, que carece, por certo de mais dados e estudos, que os números demonstram que em $2014^{26}$ e $2015^{27}$ houve pouca variação do número de demandas processuais ingressadas pelo Ministério Público. Isso pode significar a necessidade de uma revisão de sua atuação, pois mesmo que o trabalho seja realizado com excelência, pode-se não estar identificando o foco do problema ambiental em análise macro.

\footnotetext{
25 SANTA CATARINA. Ministério Público. Relatório de gestão institucional 2015. Florianópolis: MPSC, $2016 . \quad$ Disponível em: https://documentos.mpsc.mp.br/portal/manager/resourcesDB.aspx?path=1965. Acesso em 10 fev. 2017. P. 169.

26 SANTA CATARINA. Ministério Público. Relatório de gestão institucional 2014. Florianópolis: MPSC, $2015 . \quad$ Disponível em: https://documentos.mpsc.mp.br/portal/manager/resourcesDB.aspx?path=813. Acesso em 10 fev. 2017.

27 SANTA CATARINA. Ministério Público. Relatório de gestão institucional 2015. Florianópolis: MPSC, $2016 . \quad$ Disponível em: https://documentos.mpsc.mp.br/portal/manager/resourcesDB.aspx?path=1965. Acesso em 10 fev. 2017.
} 
ZIESEMER, Henrique da Rosa; HÜLSE, Levi. A retórica da defesa do Meio Ambiente - uma perspectiva catarinense do Ministério Público. Revista Eletrônica Direito e Política, Programa de Pós-Graduação Stricto Sensu em Ciência Jurídica da UNIVALI, Itajaí, v.12, n.3, $3^{\circ}$ quadrimestre de 2017. Disponível em: www.univali.br/direitoepolitica - ISSN 1980-7791

A não diminuição de demandas induz que ano a ano semelhantes problemas ambientais continuam a ocorrer e que as ferramentas utilizadas não dão conta de estancar a deterioração ambiental. A necessidade de uma revisão de postura funcional passa por uma reavaliação de identidade institucional, onde o Ministério Público, outrora concebido, e sempre foi visto tradicionalmente como órgão acusador, com evidente atuação demandista, ou seja, há muito tempo o trabalho da instituição se encerrava, em tese, como ajuizamento de alguma ação judicial.

Atualmente, a defesa da sociedade exige uma postura mais resolutiva, a fim de se adaptar às demandas sociais atuais. Outras formas de atuação ministerial devem ser incentivadas, a fim de que a busca pela sustentabilidade, em todos os seus vieses, possa se dar o mais perto possível do ideal.

A atuação extrajudicial tem ganhado força, porquanto consiste em fonte de material para a efetivação e realização das atribuições institucionais. Não se pode deixar de apontar que esta mesma atividade extrajudicial também, por vezes, abre outro caminho que não a disputa judicial, para a solução de litígios de grande importância.

A atuação do Ministério Público é bastante ampla e direcionada, em suma, na busca do bem comum. Ressalte-se que a independência funcional contribui para 0 cumprimento de suas tarefas. Sem ela não haveria sentido de dotar a instituição de tais poderes e prerrogativas, máxime contra a Administração.

Os dados trazidos comprovam a atuação Ministerial, demonstrando efetivo cumprimento nos dispositivos legais, contudo, ainda são necessários estudos e ajustes para que a finalidade plena possa realmente ser atingida, como apregoa o Art. 225 da Constituição. 
ZIESEMER, Henrique da Rosa; HÜLSE, Levi. A retórica da defesa do Meio Ambiente - uma perspectiva catarinense do Ministério Público. Revista Eletrônica Direito e Política, Programa de Pós-Graduação Stricto Sensu em Ciência Jurídica da UNIVALI, Itajaí, v.12, n.3, 30 quadrimestre de 2017. Disponível em: www.univali.br/direitoepolitica - ISSN 1980-7791

\section{CONSIDERAÇÕES FINAIS}

De todo o exposto nas linhas anteriores, algumas considerações são possíveis. Apesar de alguns avanços na defesa do meio ambiente ecologicamente equilibrado, o Estado brasileiro ainda não evoluiu ao ponto de equilibrar a pauta econômica com a ambiental. Esta dicotomia, aliás, parece ser o principal dilema quando o tema "meio ambiente" está em jogo. É certo que de nada adiantará toda a riqueza e prosperidade que uma sociedade puder produzir, se não houve um meio ambiente que garanta qualidade de vida a seus ocupantes.

A preocupação com a presente e futuras gerações deve estar sempre em pauta, aliada aos conceitos de sustentabilidade. Na tentativa de lidar com a complexa questão, o Estado criou e permitiu a criação na esfera privada, de entidades cuja função é defender o meio ambiente. Além das ramificações do Poder Executivo, como as secretarias, fundações, entre outras, há uma instituição independente, o Ministério Público, a qual foi conferida tal missão, como uma série de ferramentas para o desempenho de seu mister.

De tudo aquilo que foi analisado, tem-se que os dados mencionados são incipientes, mas demonstram que há um efetivo combate ministerial às infrações ambientais, em Santa Catarina. Contudo, em que pese o esforço reconhecido, observou-se que este não se traduziu em diminuição real das infrações ambientais, porquanto os números de combate permanecem estáveis. Vale dizer, os problemas e degradação ambiental não cedem, ao menos em números.

Isso sugere uma mudança de atuação, e uma política pública diferenciada voltada ao tema. A transformação, ou ao menos a incursão do Ministério Público, de demandista em resolutivo poderia surtir mais efeito, trabalhando de forma preventiva, e não tanto reativa. É bem verdade que dos dados mencionados, também se observou que esta mudança já está acontecendo, mas talvez não na velocidade necessária. Também importante ponderar que o Ministério Público sozinho não pode ser alçado à categoria de salvador ou responsável pela correção 
ZIESEMER, Henrique da Rosa; HÜLSE, Levi. A retórica da defesa do Meio Ambiente - uma perspectiva catarinense do Ministério Público. Revista Eletrônica Direito e Política, Programa de Pós-Graduação Stricto Sensu em Ciência Jurídica da UNIVALI, Itajaí, v.12, n.3, 30 quadrimestre de 2017. Disponível em: www.univali.br/direitoepolitica - ISSN 1980-7791

de todas as mazelas. A autocrítica é sempre necessária, pois ainda há muito o que se aprimorar.

\section{REFERÊNCIA DAS FONTES CITADAS}

BRASIL. Constituição (1988). Constituição da República Federativa do Brasil. Brasília, DF: Senado Federal: Centro Gráfico, 1988. 292 p.

BRASIL. Lei no 5.172, de 25 de outubro de 1966. Dispõe sobre o Sistema Tributário Nacional e institui normas gerais de direito tributário aplicáveis à União, Estados e Municípios.Código Tributário Nacional. disponível em http://www.planalto.gov.br/ccivil_03/leis/L5172Compilado.htm. Acesso em 10 fev. 2017.

BRASIL. Lei 0 7.347, de 24 de julho de 1985, Disciplina a ação civil pública de responsabilidade por danos causados ao meio-ambiente, ao consumidor, a bens e direitos de valor artístico, estético, histórico, turístico e paisagístico e dá outras providências. Publicado no D.O.U em 25.7.1985. Dispovel em http://www.planalto.gov.br/ccivil_03/leis/L7347orig.htm. Acesso em 10 fev. 2017.

BRASIL. Lei 8.078, de 11.9.1990. Dispõe sobre a proteção do consumidor e dá outras providências. Publicado no DOU de 12.9.1990.

BRASIL. Lei no 9.099 de 26 de setembro de 1995. Dispõe sobre os Juizados Especiais Cíveis e Criminais e dá outras providências. Disponível em http://www.planalto.gov.br/ccivil_03/leis/L9099.htm. Acesso em 10 fev. 2017.

BRASIL. Supremo tribunal Federal. RE 576155 / DF - DISTRITO FEDERAL. Relator(a): Min. RICARDO LEWANDOWSKI. Julgamento: 12/08/2010. Órgão Julgador: Tribunal Pleno. DJe-226 DIVULG 24-11-2010 PUBLIC 25-11-2010. REPUBLICAÇÃO: DJe-020 DIVULG 31-01-2011 PUBLIC 01-02-2011.

BOSSELMANN, Klaus. O princípio da sustentabilidade: transformando direito e governança. Tradução de Phillip Gil França. São Paulo: Revista dos Tribunais, 2015

LOPES, Uaçai de Magalhães; TENÓRIO, Robinson Moreira. Educação como fundamento da sustentabilidade. Salvador: EDUFBA, 2011. p.76.

MEIRELLES. Hely Lopes. Direito Administrativo Brasileiro. São Paulo: Malheiros, 26.ed., 2001

MIKHAILOVA, Irina. SUSTENTABILIDADE: EVOLUÇÃO DOS CONCEITOS TEÓRICOS E OS PROBLEMAS DA MENSURAÇÃO PRÁTICA. Revista Economia e Desenvolvimento, ISSN: 1414-6509. $n^{\circ}$ 16, 2004. p.22-41. 
ZIESEMER, Henrique da Rosa; HÜLSE, Levi. A retórica da defesa do Meio Ambiente - uma perspectiva catarinense do Ministério Público. Revista Eletrônica Direito e Política, Programa de Pós-Graduação Stricto Sensu em Ciência Jurídica da UNIVALI, Itajaí, v.12, n.3, 30 quadrimestre de 2017. Disponível em: www.univali.br/direitoepolitica - ISSN 1980-7791

SANTA CATARINA. Ministério Público. Relatório de gestão institucional 2014. Florianópolis: MPSC, $2015 . \quad$ Disponível em: https://documentos.mpsc.mp.br/portal/manager/resourcesDB.aspx?path $=813$. Acesso em 10 fev. 2017.

SANTA CATARINA. Ministério Público. Relatório de gestão institucional 2015. Florianópolis: $\quad$ MPSC, $2016 . \quad$ Disponível em: https://documentos.mpsc.mp.br/portal/manager/resourcesDB.aspx?path $=1965$. Acesso em 10 fev. 2017.

Submetido em: maio de 2017

Aprovado em: junho de 2017 